Research Article in Social Study

\title{
The Influence of Nature and Nurture
}

Nickey Zhang1,*

${ }^{1}$ Liberty High School, Sykesville, MD 21784, USA

*Correspondence: nickeyz1224@gmail.com

(Received: 12/31/2020; Accepted: 01/04/2021; Published: 03/18/2021)

DOI: https://doi.org/10.37906/isteamc.2021.5

Abstract: Nature and nurture have been a topic of discussion for years, and yet there has been no final conclusion on what is most important. This research paper goes through the process of discovering which of the two influences the human person more, along with how, and why. Information specifically regarding the relation of nature and nurture on both health and personality are included, with given descriptions of different health conditions and situations that may cause them. Discussions on what causes different health conditions and the largest factor in those health conditions are used to determine the importance of either genes or environment. The involvement of the personalities and information of serial killers are present in this paper and serve as the biggest connection between personality and environment. How ever, the final conclusion of this paper is that there is no true side that overpowers the other, and the entanglement of nature and nurture are so close that it is near impossible to know which is more important, especially w ith the current research present.

Keywords: Nature v Nurture, Psychology, Genes and Environment, Health, Personality, Epigenetics

\section{Introduction}

Psychologist Sir Francis Galton first brought about the term 'nature vs nurture' in 1869, howev er, information on who originally described the influence of genes versus the impact of the surrounding environment remains unknown (Bynum, 2002). As the conclusion of many sources gathered, it is of universal understanding that we, as humans with different morals, personalities, beliefs, and health, are a result of both nature and nurture. Our genetic makeup, pieced together with how we grew up, create the people we are today. How ever, while it is understood that both of these parts influence who we are, how much of each part makes us? Does nature influence our talents more? Or does nurture allow us to create masterpieces? Why? What makes each influence more or less impactful?

How much of your personality, intelligence, mental health, behavior, belief, or religion is dependent on nature, as opposed to nurture, and vice versa? How ever, nature vs nurture has been a subject studied by many, and there is an abundant amount of information regarding this topic. As a result, the subjects for this paper have been narrowed down to three topics, them being health, skill, and personality. We will be studying the extent of the influence of both nature and nurture, and determine what influences these three categories more. 
Nature and nurture go hand in hand in the making of a human being, due to the correlation that they have with each other, how ever, the influence of nurture far outweighs the genetic makeup of a person, because health is a result of effort, and experience forms the personality.

\section{Health}

To begin, there is a basic understanding that, yes, the biological makeup of a person is mostly due to the genetics passed onto them; the DNA given to them. How ever, even the physical features of a person are due to both genes and environment. For example, with the normal biological gene for the normal number of fingers and toes, the child should be born with that number of fingers and toes. How ever, that is also with the normal environmental influences. Due to this, had the mother smoked, or had not acted accordingly to what the doctor instructed, the child may not end up with the proper number of fingers and toes (Schneider, 2007). This shows that while it seems obvious that the biological makeup of a person determines their physical attributes, there is a portion of those physical attributes that is due to the environment that the mother had made for the child. Say, if the mother had done excessive exercise during the pregnancy? Or, perhaps, the mother had severe depression during this period, how does that influence the child inside of her?

Research has been targeted at these specific issues. Information from March of Dimes (2019) states that if the mother had depression during pregnancy, there is likelihood that the baby may bebor n prematurely, have lower weight than they should, or have developmental issues, as compared to their peers. They may struggle with attention, patience, physical activity, learning, and basic behavioral standards. Through this research, it can be noted that it is not only the genes of the child that influencehow the child develops, both mentally and physically. Physically, in regard to the fact that they may weigh less than they should both in the mother's stomach, called small for gestational age (SGA), and after they are born, known as low birthw eight (LBW). Due to this, babies may have health conditions like meconium aspiration, which may result in difficulty in breathing, Hypoglycemia, which is low blood sugar, or Polycythemia, which is the production of too many red blood cells. Babies may also have decreased oxygen levels, struggle with maintaining a normal body temperature, or struggle with adapting outside of the mother after the delivery of the child (Children's Hospital of Philadelphia). The Children's Hospital of Philadelphia also states that SGA can also be a result of the mother having "high blood pressure, chronic kidney disease, advanced diabetes, heart or respiratory disease, infection". How ever, while those are mostly genetic factors that the mother cannot control, SGA can also be developed from the mother having malnutrition or anemia, or can be a result of substance use like alcohol or drugs, along with cigarette smoking (Children's Hospital of Philadelphia).

With the abundant amount of health concerns that derive from just SGA, it is clear that both genes and outside factors influence health conditions like these, even before the child is born. However, it has already been made known that both nature and nurture influence the child. So, which influences the child more?

Through the research of SGA, it seems as though there is an even number of factors that may lead to the size of the baby before delivery. Both nature and nurture seem to influence the child equally, in just the primary aspect of SGA. So, what about other health issues that are a result of depression of the mother?

Looking at low birthweight, "the primary cause of low birthweight is premature birth" (Children's Hospital of Philadelphia). Firstly, as noted before, depression in the mother can result in premature birth, and in turn, cause low birth weight. Race, age, the number of births that the mother has had, along with 
the health of the mother, also influences who may have LBW (Children's Hospital of Philadelphia). African American babies, compared to Caucasian babies, are two times more likely to have low birthweight (Children's Hospital of Philadelphia). Race is a factor that is mostly genetic, as compared to the amount of births or the mother's health. The higher number of births, along with use of substance or malnutrition during pregnancy also increases the likelihood of LBW. Most of these factors are environmental, with the exception of race, which is genetic.

Another cause of LBW is intrauterine grow th restriction (IUGR), which is "when a baby does not grow well during pregnancy because of problems with the placenta, the mother's health, or the baby's condition" (Children's Hospital of Philadelphia). IUGR, in relation to the mother, is due to the health of the mother, which can be due to both genetic and environmental issues. Issues with the placenta, which is an organ that develops during pregnancy to help provide nutrients and oxygen to the baby may occur due to age, high blood pressure, blood clotting disorders, previous pregnancies, previous placental problems, abdominal trauma, or substance use (Mayo Clinic Staff, 2020). In this list of causes, there are many more environmental factors, or nurture habits, that cause placenta issues.

These health issues are mostly if the genetics of the mother are, for lack of a better word, "normal". How ever, on the nature aspect of health, there are a series of genetic disorders that are a result of genetic mutations, or a change in DNA from thenormal sequence. They can be caused by onegene, multiple genes, or be "a combination of gene mutations and environmental factors, or by damage to chromosomes" (National Human Genome Research Institute, 2018). Genetic disorders are mostly through nature, but can also be influenced by the environment, or surroundings, of which w ould be the impact of nurture. "Some diseases are caused by mutations that are inherited from the parents and are present in an individual at birth... other diseases are caused by acquired mutations in a gene... during a person's life. [... These occur randomly ...] or due to some environmental exposure" (National Human Genome Research Institute, 2018).

While these are genetic disorders, the cause of them is not solely genetic. In fact, many examples of these genetic disorders are thought to be both causes of nature and nurture. How ever, which one is more influential?

Autism is a very popularly known genetic disorder that lacks definitive information on the originations, or the formations of the mutation in the gene. It is known to develop before 3 years of age, and influences children in varying ways, the most common being impaired social interaction (National Human Genome Research Institute, 2019). In the research given by the National Human Genome Research Institute (2019), it was concluded that while autism has an unknown cause, it is most likely due to b oth genetics and environment. It is difficult to completely determine the origin of autism, or how much of either nature or nurture influences autism. How ever, with the determining statement that it is likely a result of both nature and nurture, another example of a genetic disorder is cancer. Specifically, the focus will be on breast cancer.

Breast cancer is extremely common, with statistics stating that "one in nine American women will develop breast cancer in her lifetime" (National Human Genome Research Institute, 2014). There is an estimation of about 5 to 10 percent that breast cancer is developed from hereditary causes (American Cancer Society, 2019). Children of parents with the gene mutation for breast cancer have a 50 percent chance of inheriting that gene, which may later develop into breast cancer. (National Human Genome Research Institute, 2014). This brings the conclusion that while genetic disorders are thought to be mostly nature, it is, to an extent, also largely influenced by outside factors, or the nurture factor. 


\section{Epigenetics}

Throughout the health portion of this essay, the primary source of proof has been the relation of disease, or issues in health, due to the surrounding environment. How ever, it has been mostly from both nature and nurture, with a lot of information guiding tow ards nurture. It is quite true that both nature and nurture go hand in hand, and with that, the word "epigenetics" forms.

To one, the original thought of genetics, or DNA, brings immediate connection to nature, or the biological formation of a person. However, epigenetics, while involving genes, is the influence of outside factors that change the genes. It does not change the fundamental aspect of the gene; however, it does influence how the gene is read by the cells (Alegría-Torres et al., 2011). Outside factors like diet, stress, physical activity, substance/cigarette use, or sleeping habits may impact disease, conditions, developments of the brain, or the length of life (Alegría-Torres et al., 2011).

For a very basic example, epigenetics are what is in play if one is obese, which may then lead into cancer or heart disease (Alegría-Torres et al., 2011). Due to the diet of the person, and how they took care of their body, which are all outside, nurture habits, it caused their body, their inner biology, to be endangered.

Due to the intimate connection between surroundings and biology, "the very concept of a gene requires the environment" (Schneider, 2007). Genes are a result of both the biological DNA passed down through generations, combined with outside factors of the surrounding environment, or influences, to make a person who they are. Epigenetics are the results of the environment and outside factors, which then make nurture such a big part in health and daily life. Epigenetics are proof that nature is directly influenced by nurture, and as a result, influence the health of the person, both mentally and physically.

\section{Personality}

Personality is almost completely different in everyone. Similar people may relate with one another; how ever, personalities can't be put into definitive groups. As a result of this, the best way to begin would be with the extremities, which are serial killers.

Already, the first conclusion is that serial killers are created through nurture. Arikan's (2015) statement of "Parental attitudes, upbringing style, social relations, social-economical problems are the most important signals of creating a serial killer." These are all in relation to the nurture aspect of the spectrum. The way these serial killers grew up, their living environment and how they were treated, are all factors in making them the person they are today, with the personality that they have. Additional information from the American Academy of Experts in Traumatic Stress state that "those who were animal abusers were five times more likely to commit acts of violence such as assault, rape, and murder against others." How ever, the very cause of children abusing animals is due to the helplessness they felt as a result of the control their parents had over them. This resulted in the act of torturing animals to express the powerlessness they felt, because it gave the child power over the animal (American Academy of Experts in Traumatic Stress). Violent acts can be completely drawn to the very beginning of the child's life, and through this evidence, it is acknowledged that this is mostly due to nurture. How ever, how much does nurture influence the human brain? Many people go through trauma, and yet only a specific group of people decide to kill as a result of that trauma. Does this have a connection with the biological nature of these serial killers?

There was a study done by criminologist Eric Hicky, that in a room of 62 male serial killers, 48 percent of them were "rejected as children by a parent or some other important person in their lives" (American 
Academy of Experts in Traumatic Stress). This shows that the development of these serial killers, the nurturing environment surrounding them, plays a pretty large part in creating the person that they are. However, what about the other half?

Through research, there was an inability to provide any evidence of a serial killer that came from a good home or grew up in a well-maintained childhood, or didn't have any traumatic experiences or substance use. Serial killer Joanna Dennehy grew up in a stable home with loving family members, and had done well in school prior to her late teenage years (Crime Investigation). How ever, during her teenage years, she began to use substances and got involved in small crimes. It was during this time that her development of narcissism, manipulation, and anti-social personality disorder became noticeable (Crime Investigation). Dennehy was one of the few serial killers found to have a loving childhood without any specific trauma related to important figures in life. However, in her decent to substance use and involvement with the wrong group of people, she had followed the path of serial killing, which, after the inclusion of these factors, resonates as to why shebecame a serial killer. The process of which one becomes a serial killer may sometimes follow the path of "a three-part progression from burglary to sexual assault to murder" (Martin et al., 2020). With this evidence, it is proven that nurture has a lot more involvement in the personality and the creation of serial killers as compared to nature.

How ever, even with the major impact of nurture, it has been discovered that there may be a possibility that serial killers contain a specific genetic makeup that makes them more prone to killing, or to gain pleasure from killing. Brain scans were done on over 500 people, varying between those who were prone to violence, and those who were considered "normal". It was found that "the brain images of those who had been convicted of a murder with aggressive or antisocial disorders showed distinct brain activity compared to those who were considered normal" (American Academy of Experts in Traumatic Stress). This study was done in 2000, how ever, if the results of this experiment are correct, it proves that serial killers have a completely different biological nature than non-violent individuals (American Academy of Experts in Traumatic Stress). This then involves nature, as expected. Information about increased testosterone in males may also lead to the possibility of biological reasons for serial killing (Arikan, 2015).

Even with the heavy involvement of surrounding environment, child hood trauma, and experiences that create the serial killer, there is still proven evidence that nature is partially involved. But knowledge that both nature and nurture are involved is not new information. How ever, the amount of influence that nature has over serial killers may be unexpected. Not only is excess testosterone and distinct brain activity a possiblebiological factor in serial killers, the orbital frontal cortex and anterior cingulated cortex in serial killers as compared to normal people is vastly different. The orbital frontal cortex controls emotional outbursts, and the anterior cingulated cortex controls responses to conflict (American Academy of Experts in Traumatic Stress). In serial killers, it w as found that this entire portion of the br ain w as minimal, or even non-existent, and the part of the brain that controls reactions to fear w as average, or higher, than the normal person (American Academy of Experts in Traumatic Stress). This evidenceleads to the understanding that nature also plays a large role in the creation of serial killers. Perhaps they are born, and not made.

\section{Limitations and Recommendations}

With the addition of longitudinal studies and research, there is the possibility of finally understanding what truly impacts a person, and how nature and nurture, which are so carefully w oven together, are able to be separated and picked apart. 
Further studies on the proper environment for the child, and how to properly nurture talent, or expand on the developmental process of the human brain. There are many psychological illnesses that develop during trauma, at any moment in time, and further studies on whether some people with families who are already psychologically ill are more prone to that. How much your genes truly impact you, and how to be able to create an environment that is able to nurture your genes into something beautiful, so that people can grow and become the best versions of themselves. Knowing the connection betw een nature and nurture would be able to assist many people, not just parents, by finally allowing people to understand why they are the way they are, and to begin to problem-solveby the very root of the issue.

Future research on this topic would largely benefit the community, and longitudinal studies would allow for a more accurate and deeper verdict of what truly makes the human who they are.

\section{Conclusions}

Nature and nurture are so entwined that it is virtually impossible to determine whether it is either nature or nurture that influences someone more. This essay only looked at surface level parts of nature and nurture, and determined, very vaguely, that nurture holds more impact. However, even with years of studies, paired with hundreds of scientists, there seems to be no absolute answer to what makes a person the way they are. Biologically, our bodies create chemicals to make us happy, like "end orphin, oxy tocin, serotonin, and dopamine" (Psychologies, 2018), how ever, these chemicals are created as a result of outside factors that are not related to biology. Nature and nurture have alw ays been debated over, to decide what is more important, or more influential, or what is the best way to raise a child, or to have a healthier life. The final determining factor w ould be that there is no answer to this question. Neither nature nor nurture is more important, because they are both as influential. How ever, due to the fact that nurture is virtually the only thing that humans have pow er over, it seems as though nurture far outw eighs the impact of nature. If forced to choose, many w ould conclude that nurture is more influential. If I w as forced to choose, I w ould also agree that nurture is more influential. But we cannot disregard how connected nature and nurture are with each other. Even with the most obvious statement, seemingly in support of only one side, holds possibilities of the presence of the opposing side. Nature and nurture have never been on opposing sides, because they create the person through entangled threads, without knowing which is which and what is what.

As a result, the final verdict of this paper is that on a surface level, the obvious answer of nurture is present, and has the most impact on a person. How ever, our current extent of research is unable to provide an accurate decision on which is more influential, other than the fact that both nature and nurture is necessary for almost all aspects of human life.

\section{References}

“About Autism" (2019, May 19). National Human Genome Research Institute. https://www.genome.gov/Genetic-Disorders/Autism.

“About Breast Cancer" (2014, Nov 7). National Human Genome Research Institute. https://www.genome.gov/Genetic-Disorders/Breast-Cancer. 
Alegría-Torres, J. A., Baccarelli, A., \& Bollati, V. (2011). Epigenetics and lifestyle. Epigenomics, 3(3), 267277. https://doi.org/10.2217/epi.11.22

American Academy of Experts in Traumatic Stress.(n.d.) Associatedcontent.com.

https://www.aaets.org/traumatic-stress-library/serial-killer-nature-vs-nurture-how-serial-killersare-born.

Arikan, H. E. (2015, June). Serial Killers: Nature Vs. Nurture. Research Gate. https://www.researchgate.net/publication/279198129_SERIAL_KILLERS_NATURE_vs_NURTURE \#: :text=Nature\%20nurture\%20debate\%20is\%20the,order\%20to\%20violence\%20and\%20crime.

"Breast Cancer Risk Factors You Cannot Change" (2019, Sept 10). American Cancer Society. https://www.cancer.org/cancer/breast-cancer/risk-and-prevention/breast-cancer-risk-factorsyou-cannotchange.html\#: :text=About\%205\%25\%20to\%2010\%25\%20of,the\%20BRCA1\%20or\%20BRCA2\%2 Ogene.

Bynum, W. F. (2002). The childless father of eugenics. Science 296, 472. doi: 10.1126/science.1069041

“Depression During Pregnancy". (2019, March). March of Dimes. https://www.marchofdimes.org/complications/depression-during-pregnancy.aspx\#.

“Genetic Disorders" (2018, May 18). National Human Genome Research Institute. https://www.genome.gov/For-Patients-and-Families/Genetic-Disorders.

“Joanne Dennehy" (n.d.). Crime Investigation. https://www.crimeandinvestigation.co.uk/crimefiles/joanne-dennehy/biography.

"Low Birthweight". (n.d.) Children's Hospital of Philadelphia.https://www.chop.edu/conditionsdiseases/low-

birthweight\#: :text=The $\% 20$ primary $\% 20$ cause $\% 20$ of $\% 201$ ow, the $\% 201$ latter $\% 20$ part $\% 20$ of $\% 20$ pr egn ancy.

Martin, E., Schwarting D. E., Chase R. J. (2020, June 15). Serial Killer Connections Through Cold Cases. National Institute of Justice. https://nij.ojp.gov/topics/articles/serial-killer-connections-throughcold-cases.

Mayo Clinic Staff (2020, March 25). "Placenta: How it works, what's normal". Mayo Clinic. https://www.mayoclinic.org/healthy-lifestyle/pregnancy-week-by-week/in-depth/placenta/art$\underline{20044425}$.

Psychologies (2018, Apr 14). "Boost your natural 'feel good' chemicals". Psychologies. https://www.psychologies.co.uk/self/how-to-boost-your-natural-feelgood-chemicals.html.

"Small for Gestational Age". (n.d.). Children's Hospital of Philadelphia. https://www.chop.edu/conditions-diseases/small-gestational-age\#. 